\title{
Shoot multiplication of Pogostemon cablin var. Sidikalang and patchouli oil profile
}

\author{
POPY HARTATIE HARDJO`, DANNY PUTRA SENTOSA SUSANTO, WINA DIAN SAVITRI, \\ MARIA GORETTI MARIANTI PURWANTO \\ Faculty of Biotechnology, Universitas Surabaya. Jl. Raya Kalirungkut, Surabaya 60292, East Java, Indonesia. \\ Tel.: +62-31-2981399, Fax.: +62-31-2981278. `email: poppy_hardjo@staff.ubaya.ac.id.
}

Manuscript received: 11 February 2019. Revision accepted: 13 June 2019.

\begin{abstract}
Hardjo PH, Susanto DPS, Savitri WD, Purwanto MGM. 2019. Shoot multiplication of Pogostemon cablin var. Sidikalang and patchouli oil profile. Nusantara Bioscience 11: 123-127. Pogostemon cablin Benth. is a plant producing patchouli oil, which mostly consists of patchouli alcohol compound. Patchouli oil has great potentials in the world market because of its stability and high price. In this study, in vitro multiplication of Sidikalang variety of Acehnese patchouli shoots was done on solid and liquid Murashige \& Skoog (MS) medium. This study aimed to determine the effect of cytokinins in various combinations of shoot multiplication and to compare the patchouli oil yield of in vitro and ex vitro culture. In vitro multiplication of Acehnese patchouli shoots by using solid MS medium with addition of $0.2 \mathrm{ppm}$ benzyl aminopurine (BAP) and $0.2 \mathrm{ppm}$ Kinetin resulted in shoot explants with an average growth index of $82.198 \pm 0.690$. Patchouli oil extraction was done on 7 weeks old in vitro shoot explants cultured on solid MS medium $+0.2 \mathrm{ppm}$ BAP $+0.2 \mathrm{ppm}$ Kinetin using water distillation method. In vitro shoots yielded $2.5 \%$ patchouli oil and contained $\pm 35 \%$ patchouli alcohol compound, whereas ex vitro shoots produced $4 \%$ patchouli oil and contained $\pm 25 \%$ patchouli alcohol compound. The qualitative analysis by using thin layer chromatography (TLC) showed that there were similarities in the number of spot and Rf value for each spot of ex vitro and in vitro patchouli oil.
\end{abstract}

Keywords: Patchouli oil, Pogostemon cablin, shoot multiplication, var. Sidikalang

\section{INTRODUCTION}

Patchouli is an essential oil producing plant. The oil extracted from the leaf part of Acehnese patchouli (Pogostemon cablin Benth.) var Sidikalang (is called patchouli oil) is the best in Indonesia and has the high value in the international trade (Wu et al, 2013). Patchouli oil is utilized in perfume industry as a fixative agent. Beside of that, in the recent years, patchouli oil is also known to have some benefits as aromatherapy (Ito et al, 2015), e. g. to calm nerves and to relieve stress. It is also potential to combat pathogenic microorganism as it has biological activity such as antibacterial (Yan et al. 2013), anti-inflammatory (Han et al. 2017), and antioxidant (Dechayont et al. 2017).

The issue in patchouli oil industry in Indonesia is the diversity of patchouli oil's quality. This problem may be caused by the breeding system that is affected by the fluctuating environmental condition (Blank et al, 2011). Thus, as the alternative, plant tissue culture technique was developed to achieve homogeneity of raw material to produce patchouli oil.

The utilization of tissue culture technique to produce patchouli oil from the leaf part of patchouli as the raw material intended to obtain patchouli oil with high rendement and quality, where the leaf growth was controlled by nutrient and mineral factor, and also light intensity in in vitro environmental condition. In addition, the supply of raw material (in vitro leaves) was continuing and not depending on the season. The patchouli oil was obtained from the leaf part, particularly the glandular trichomes on the leaf surface. Maes and Goossens (2010) stated that benzyl aminopurine (BAP) and jasmonic acid could increase the number of trichomes in Arabidopsis' leaf.

Multiplication of in vitro shoots of $P$. cablin on solid MS medium has been widely researched (Swamy et al. 2016) used $0.5 \mathrm{mg} . \mathrm{L}^{-1} \mathrm{BAP}+0.5 \mathrm{mg} . \mathrm{L}^{-1} \mathrm{Kin}$; Jin et al. (2014) used $0.2 \mathrm{mg} . \mathrm{L}^{-1} \mathrm{BAP}$, yet it has never been done before in liquid medium. The use of liquid medium in this research is an early step to figure out shoots response when they are cultured in liquid medium, also to prepare shoot culture in a bioreactor system. Sahertian (2015) reported that the highest multiplication rate of in vitro shoot of $P$. cablin var. Sidikalang was on solid MS medium with 0.5 $\mathrm{mg} . \mathrm{L}^{-1} \mathrm{BAP}$, the shoots were subsequently elongated and afterwards, the leaf size became wider after subcultured on hormone-free MS medium. In line with that, in this experiment we would be examined the effect of lower concentration of BAP and Kinetin on solid and liquid MS medium to increase the shoot multiplication as well as the leaf size, also to compare the patchouli oil profile from in vitro and ex vitro leaf. 


\section{MATERIALS AND METHODS}

\section{Procedures}

\section{Shoot multiplication}

Nodal part from patchouli plant aged 1 year, planted at greenhouse, was used as explant source. The explants were soaked in a 70\% ethanol solution for $1 \mathrm{~min}$, then subsequently washed several times with sterile distilled water. Afterwards, they were dipped in a bleaching solution (20\% Clorox) for $15 \mathrm{~min}$, and then washed many times with sterile distilled water. The nodal cuttings were cultured on MS basal medium (3\% sucrose (w/v) and $0.7 \%$ agar (w/v)) with the addition of $\left(0.2\right.$ and $\left.0.5 \mathrm{mg} . \mathrm{L}^{-1}\right)$ BAP, (0.2 and 0.5 mg. $\left.\mathrm{L}^{-1}\right)$ Kinetin, and combination of BAP and Kinetin. The explants were cultured on liquid medium with additional support such as filter paper (Vyas et al, 2008 in modification). The initial weight of shoots was weighed. The cultures were incubated at $\pm 25{ }^{\circ} \mathrm{C}$ with $16 \mathrm{~h}$ light per day for 7 weeks. The observation was performed every week, including the shoot's fresh weight and the shoot's growth index. The shoot's growth index was calculated by dividing shoot's fresh weight when observing with initial fresh weight. In the last day of week-7, where there was no more growth based on shoot's growth curve, the cultures were harvested and latterly air dried until they reached constant weight. Finally, the dried cultures were mashed into powder. The cultures which have the highest growth index were continued to analyze essential oil profiles from in vitro and ex vitro plants.

\section{Essential oil extraction by water distillation}

As much as $10 \mathrm{~g}$ dry powder was extracted by steam and water distillation at $100 \pm 2^{\circ} \mathrm{C}$ for $4 \mathrm{~h}$. The extract was transferred to separating funnel, then $5 \mathrm{ml} \mathrm{n}$-hexane solution and a sufficient amount of $\mathrm{NaCl}$ solution $(1 \mathrm{~N})$ were added in to it. The water layer at the bottom of separating funnel was removed, and then anhydrous sodium sulfate was sufficiently added. Afterwards it was filtered by filter paper. The yield or rendement of patchouli oil was calculated by the formulation below (Triesty dan Mahfud, 2017):

$$
\text { Yield }=\frac{\text { oilvolume }(\mathrm{ml})}{\text { shoot dry weight }(\mathrm{g})} \times 100 \%
$$

\section{Qualitative analysis by thin layer chromatography (TLC)}

Chromatography chamber was filled with n-hexane: ethyl acetate as a mobile phase (eluent) with a ratio of 9: 1 (Hernani 1988), the chamber was closed tightly until the atmosphere became saturated. TLC plate (TLC Silica Gel $60 \mathrm{~F}_{254}$ ) sized $10 \times 10 \mathrm{~cm}$ as stationary phase was marked $0,5 \mathrm{~cm}$ long, each from the bottom and from the top end. As much as $0,2 \mu \mathrm{L}$ patchouli oil from each standard, ex vitro shoot, and in vitro shoot was applied on the bottom mark of the plate. The plate was then put into chamber in the upright position, the chamber lid was closed tightly. The mobile phase would spread through TLC plate. After the mobile phase reached the top end mark, the plate was then taken out from the chamber. Afterwards, the resulting spots were observed under UV light at $\lambda=254 \mathrm{~nm}$.
Retention factor (Rf) value could be calculated by the formula below (Nichols, 2018):

$$
R f=\frac{\text { analyte mileage }(\mathrm{cm})}{\text { eluent mileage }(\mathrm{cm})}
$$

\section{Qualitative analysis by gas chromatography $(G C)$}

About $100 \mu \mathrm{L}$ patchouli oil from distillation result was injected to a gas chromatography tool which has been arranged in such a way. The mobile phase is helium and HP-INNOWAX (PEG) column was used as stationary phase. The solvent used was n-hexane. Analysis result by GC would appear at the computer screen in the form of peak/ spectra with particular number and pattern. Resulted peaks could be compared with the literature based on their retention time. From the chromatography results, it could be known the type and the constituents content which contained in the patchouli oil (patchouli alcohol content).

\section{Data analysis}

Every treatment was repeated 20 times with factorial treatment design. (medium consistency factors were liquid and solid, plant growth regulator factors were the combination of BAP and kinetin) performed by completely randomized design. The shoot growth index analysis was executed by two-way ANOVA which then continued with Duncan's Multiple Range Test (DMRT) at $\alpha=0.05$ to identify the differences between treatments. At the same time, patchouli alcohol content was analyzed by one-way ANOVA and also continued with DMRT at $\alpha=0.05$.

\section{RESULTS AND DISCUSSION}

Patchouli shoots grew in MS + BAP medium $0.2 \mathrm{mg} . \mathrm{L}^{-1}$ + Kin 0.2 mg. $\mathrm{L}^{-1}$ had big size and large numbers of leaves, and thick stems (Figure $1 \mathrm{C}, \mathrm{D}$ ). Addition of BAP with concentration of $0.2 \mathrm{mg} . \mathrm{L}^{-1}$ in the form of rosette (small leaves in groups) was not too much, while the addition of BAP with a concentration of $0.5 \mathrm{mg} . \mathrm{L}^{-1}$ caused large amounts of rosette buds and the tendency of explants to form callus (abnormal growth). This phenomenon occurs both in solid MS medium and liquid MS.

Patchouli shoots grew on solid MS medium + BAP 0.2 mg. $\mathrm{L}^{-1}+$ Kin $0.2 \mathrm{mg} . \mathrm{L}^{-1}$ had the highest growth index and significantly different from other patchouli explant shoot growth index at $7^{\text {th }}$ week (Table 1). Bharati (2010) stated that the addition of a combination of growth regulators BAP and Kinetin has a better impact in multiplication of Acehnese patchouli plants when compared with the addition of one. Overall, the growth of patchouli shoots is better in solid medium than liquid medium. This is likely because the culture in the liquid medium was not placed in a shaker, so that medium aeration was lacking and had a negative impact on shoot growth. In contrary, Vyas (2008) reported the stimulatory effect of liquid media supported by glass beads on the in vitro growth of four medicinally important plants. Patchouli shoots with the largest growth index value harvested after the $7^{\text {th }}$ week when the growth curve was in the stationary phase and continued with an analysis of the essential oil content. 

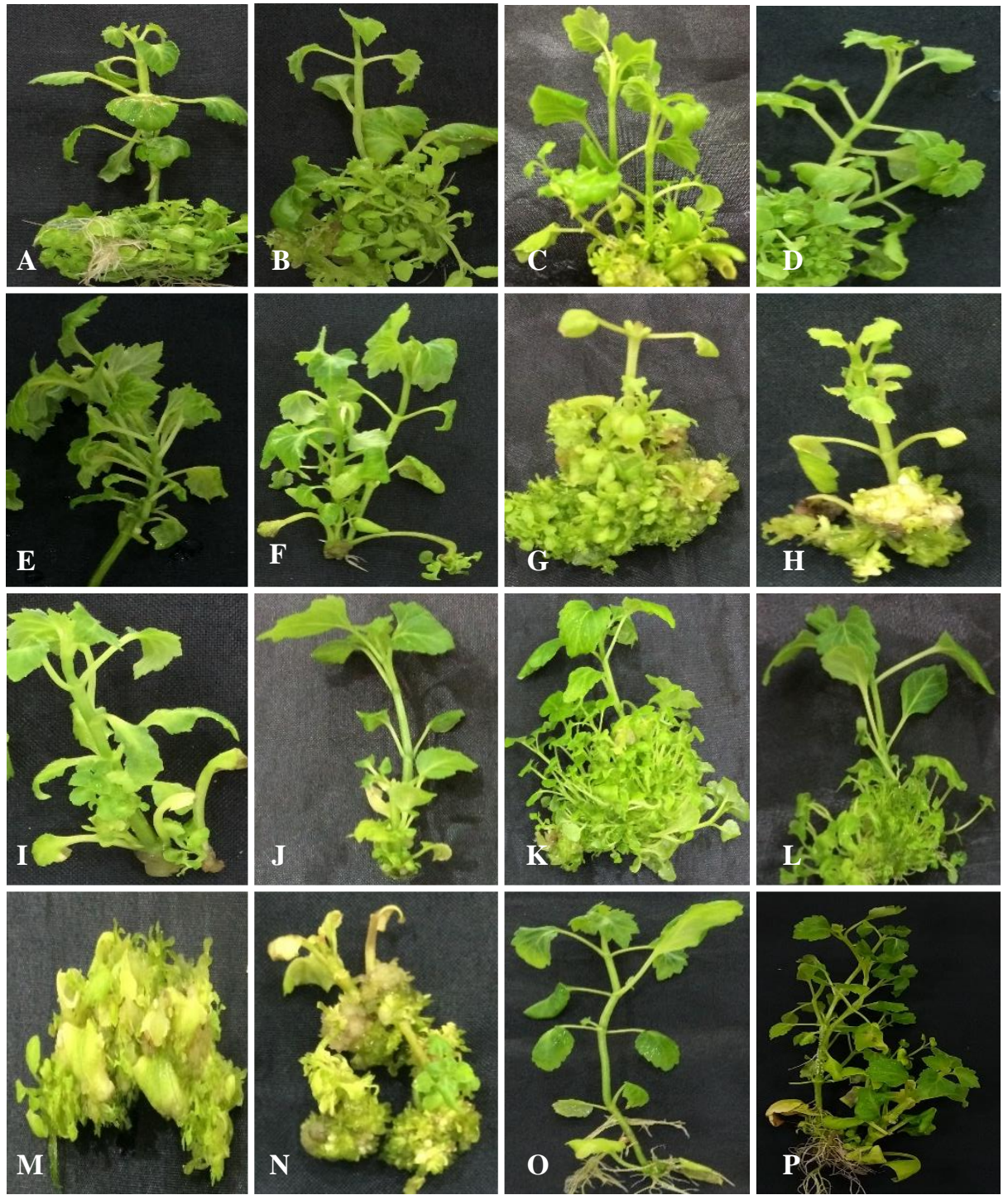

Figure 1. Morphology of In Vitro Patchouli Shoot on MS Medium with various BAP and Kinetin at 7 weeks. Note: A. MS (solid) + BAP 0.2; B. MS (liquid) + BAP 0.2; C. MS (solid)+ BAP $0.2+$ Kin 0.2 ; D. MS (liquid) + BAP $0.2+$ Kin 0.2; E. MS (solid) + Kin 0.2; F. MS (liquid) + Kin 0,2; G. MS (solid) + BAP $0.5+$ Kin 0.2; H. MS (liquid) + BAP $0.5+$ Kin 0.2; I. MS (solid) + Kin 0.5; J. MS (liquid) + Kin 0.5; K. MS (solid) + BAP $0.2+$ Kin 0.5; L. MS (liquid) + BAP $0.2+$ Kin 0.5; M. MS (solid) + BAP $0.5+$ Kin 0.5 ; N. MS (liquid) + BAP $0.5+$ Kin 0.5; O. MS (solid) 0 ; P. MS (liquid) 0 .

Table 1. Growth rate index of in vitro patchouli shoots at $7^{\text {th }}$ week on solid and liquid MS medium

\begin{tabular}{lll}
\hline \multirow{2}{*}{ Cytokinin (mg.L } & $-\mathbf{1})$ & \multicolumn{2}{c}{ Growth rate index \pm SD } \\
\cline { 2 - 3 } & Solid MS & Liquid MS \\
\hline & & \\
MS0 & $8.956 \pm 1.327^{\mathrm{a}}$ & $14.643 \pm 3.478^{\mathrm{b}}$ \\
BAP 0.2 & $51.308 \pm 0.985^{\mathrm{g}}$ & $27.366 \pm 1.719^{\mathrm{de}}$ \\
Kin 0.2 & $32.839 \pm 1.173^{\mathrm{f}}$ & $26.288 \pm 1.931^{\mathrm{de}}$ \\
BAP 0.2 + Kin 0.2 & $82.198 \pm 0.690^{\mathrm{j}}$ & $28.633 \pm 0.519^{\mathrm{e}}$ \\
Kin 0.5 & $48.798 \pm 1.640^{\mathrm{g}}$ & $25.746 \pm 0.431^{\mathrm{d}}$ \\
BAP 0.5 + Kin 0.2 & $54.925 \pm 1.166^{\mathrm{h}}$ & $20.843 \pm 0.396^{\mathrm{c}}$ \\
BAP 0.2 + Kin 0.5 & $53.902 \pm 1.476^{\mathrm{h}}$ & $22.844 \pm 0.967^{\mathrm{c}}$ \\
BAP 0.5 + Kin 0.5 & $57.812 \pm 0.526^{\mathrm{i}}$ & $23.219 \pm 1.870^{\mathrm{c}}$ \\
& & \\
\hline
\end{tabular}

Note: values followed by different letter notation means significantly different based on DMRT test at $\alpha=0.05$
Based on the growth curve of patchouli shoot explants on solid MS + BAP $0.2 \mathrm{mg} . \mathrm{L}^{-1}+$ Kin $0.2 \mathrm{mg}$. . ${ }^{-1}$ (Figure 2 ), it can be seen that in the 1 st to 2 nd week there was an increase in growth of patchouli shoot explants which is not too significant, namely from 2,187 to 4,174 . Patchouli shoot explants began to experience an exponential phase after the $2^{\text {nd }}$ week, where the patchouli shoot growth index was obtained at 14.468 at the age of 3 weeks. The largest growth occurred between the $5^{\text {th }}$ and $6^{\text {th }}$ weeks, where the initial growth index was 37.846 to 79.444 . The patchouli explant experienced a stationary phase after passing the 6th week. Patchouli shoot growth index was obtained at 82,198 at the age of 7 weeks. On the other hand, in the liquid MS medium the largest growth index growth occurred between the $4^{\text {th }}$ and $5^{\text {th }}$ week, where the initial growth index was 11.431 to 26.834 . Patchouli shoot explants experienced a stationary phase after passing the $6^{\text {th }}$ week with a growth index value of 28.633 in $7^{\text {th }}$ week of culture. 


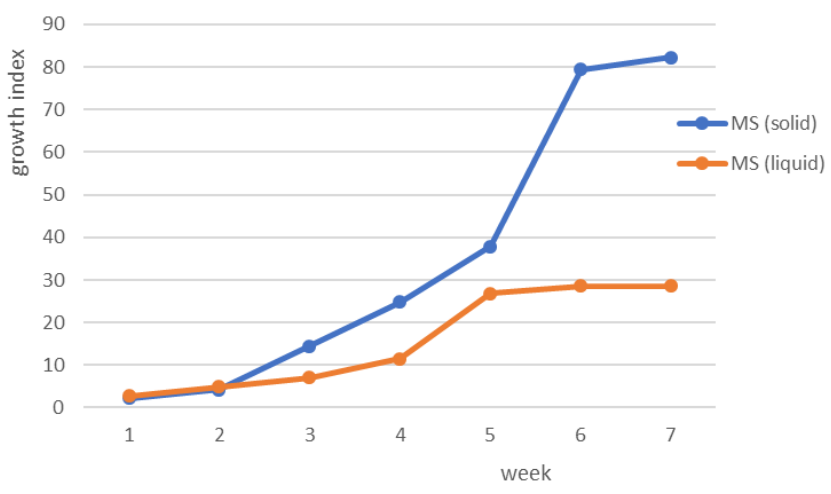

Figure 2. Growth index curve of Pogostemon cablin Benth. on MS medium with addition BAP $0.2 \mathrm{mg} . \mathrm{L}^{-1}+\mathrm{Kin} 0.2 \mathrm{mg} . \mathrm{L}^{-1}$

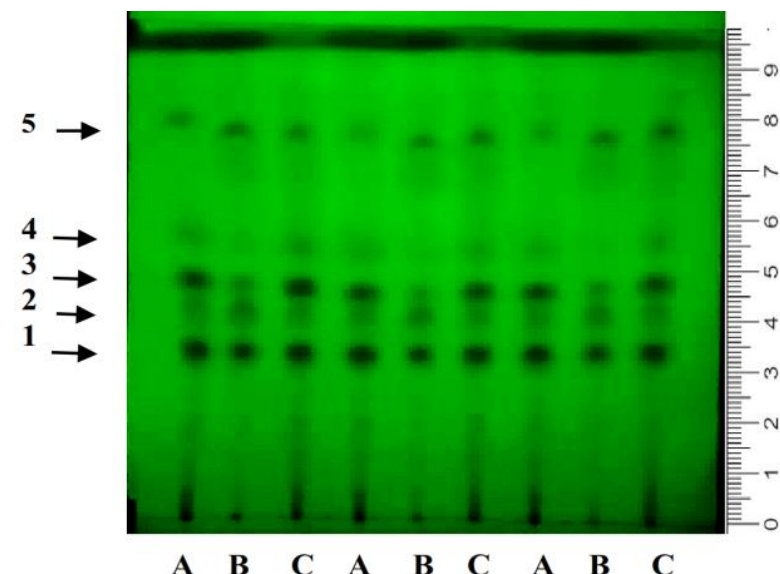

Figure 3. TLC Chromatogram of Patchouli Oil on UV $\lambda=254 n$ (A) Standard; (B) Ex Vitro; (C) In Vitro Eluent n-Hexana: Etil Asetat $=9: 1$

$\mathbf{A}$

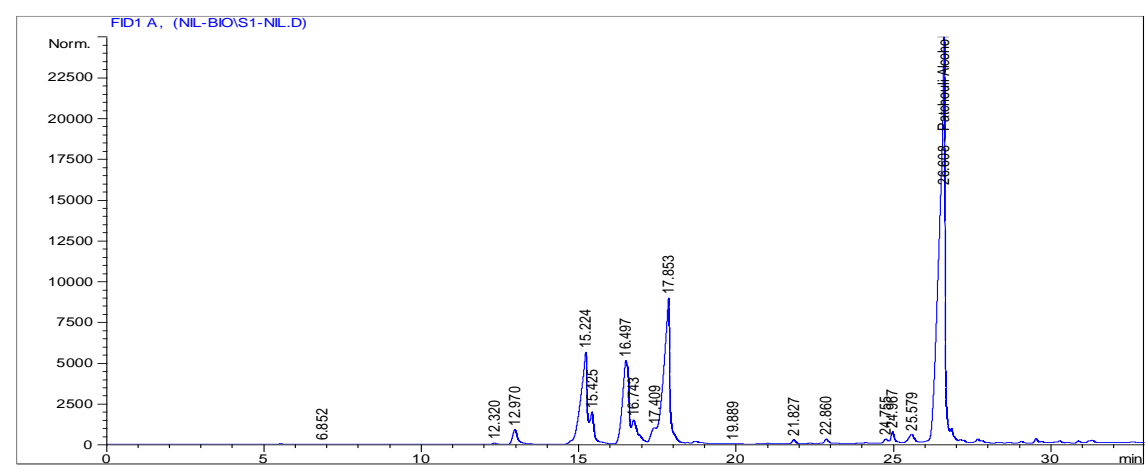

B
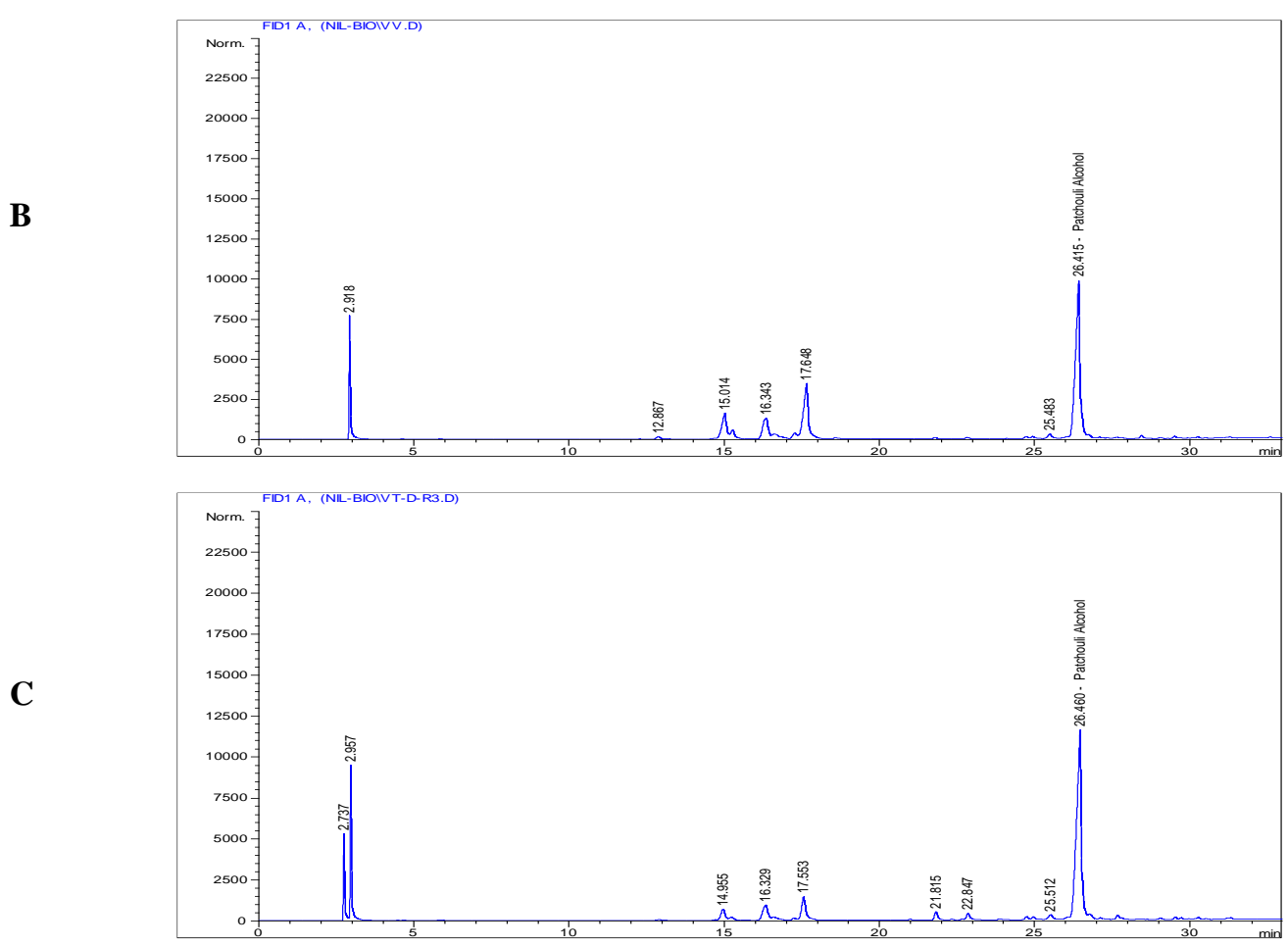

Figure 4. GC Chromatogram of patchouli oil. A. Standard; B. Ex vitro; C. In vitro HP-INNOWax column 
Table 2. Rf value of Thin Layer Chromatography (TLC) of patchouli oil

\begin{tabular}{lccc}
\hline \multirow{2}{*}{ Rf value } & \multicolumn{3}{c}{ Patchouli oil } \\
\cline { 2 - 4 } & Standard & Ex vitro & In vitro \\
\hline Spot-1 & 0.344 & 0.344 & 0.344 \\
Spot -2 & 0.411 & 0.411 & 0.411 \\
Spot -3 & 0.478 & 0.478 & 0.478 \\
Spot -4 & 0.556 & 0.556 & 0.556 \\
Spot -5 & 0.767 & 0.767 & 0.767 \\
\hline
\end{tabular}

Table 3. Patchouli alcohol (PA) level on ex vitro and in vitro patchouli oil

\begin{tabular}{lcc}
\hline Sample & $\begin{array}{c}\text { Rendement } \\
(\boldsymbol{\%})\end{array}$ & $\begin{array}{c}\text { Average of patchouli } \\
\text { alcohol level }(\%)\end{array}$ \\
\hline Standard patchouli oil & - & $40.691^{\mathrm{a}}$ \\
Ex vitro patchouli oil & 4 & $24.643^{\mathrm{b}}$ \\
In vitro patchouli oil & 2.5 & $35.206^{\mathrm{c}}$ \\
\hline
\end{tabular}

Note: values followed by different letter notation means significantly different based on DMRT test at $\alpha=0.05$

Figure 3 chromatogram showed no difference in patchouli oil profiles of in vitro and ex vitro leaves. Based on Table 2 the $\mathrm{Rf}$ values of patchouli oil in vitro and ex vitro and standard compounds were the same.

Based on the results of the gas chromatography test (Figure 4), it can be seen that standard patchouli oil, ex vitro patchouli oil, and in vitro patchouli oil have a similar retention time for patchouli alcohol which was about 26.4 minutes. Patchouli alcohol compounds in all three samples produced the highest peak when compared to other peaks formed.

Based on Table 3 it is known that the level of patchouli alcohol from patchouli oil in vitro is greater than ex vitro, but on the contrary, the rendement of patchouli oil is smaller. This indicates that the rendement of patchouli oil does not necessarily have a positive correlation with the level of patchouli alcohol in patchouli oil. Nuryani et al. (2005) stated that it is a negative correlation between the rendement of patchouli oil and the level of patchouli alcohol from Aceh patchouli (highland and lowland Acehnese patchouli). Furthermore, it is explained that Aceh patchouli grown in the lowland will produce high rendement patchouli oil but low level of patchouli alcohol. Conversely, patchouli plant grown in the highland will produce low rendement patchouli oil and high level of patchouli alcohol.

Based on our study we can conclude that: (i) The best shoot multiplication of Pogostemon cablin Benth. var. Sidikalang was on solid MS $+0.2 \mathrm{mg} \cdot \mathrm{L}^{-1} \mathrm{BAP}$ and 0.2 mg.L. $L^{-1}$ Kinetin; (ii) There was no difference on patchouli oil's profile from in vitro and ex vitro leaf of $P$. cablin var.
Sidikalang; (iii) The concentration of patchouli alcohol in in vitro leaf is higher than in ex vitro leaf of $P$. cablin var. Sidikalang.

\section{ACKNOWLEDGEMENTS}

The authors would like to thank the LPPM Ubaya for providing financial support through Competitive Research, contract No. 037/SP-Lit/LPPM-01/FTB/V/2018.

\section{REFERENCES}

Bharati N. 2002. Biotechnology in commercial production of patchouli in North Eastern Region. NEDFC and NHB 3 (2): 46 -51.

Blank AF, Sant'ana TCP, Santos PS, Blank NFA, Prata APN, Jesus HCR, Alves APB. 2011. Chemical characterization of the essential oil from patchouli accessions harvested over four seasons. Industr Crops Prod 34 (1): 831-837.

Dechayont B, Ruamdee P, Poonnaimuang S, Mokmued K, ChunthorngOn J. 2017. Antioxidant and antimicrobial activities of Pogostemon cablin (Blanco) Benth. Hindawi J Bot 2017: 1-6.

Han X, Beaumont C, Stevens N. 2017. Chemical composition analysis and in vitro biological activities of ten essential oils in human skin cells. Biochimie Open 5: 1-7.

Hernani. 1988. Analisis minyak nilam secara kromatografi lapis tipis. Buletin Littro 3 (2): 89-92. [Indonesian]

Ito K, Akahoshi Y, Ito M, Kaneko S. 2015. Sedative effects of inhaled essential oil components of traditional fragrance Pogostemon cablin leaves and their structure-activity relationships. J Trad Compl Med 2015. DOI: 10.1016/j.jtcme.2015.01.004.

Jin H, Deng ZC, He H. 2014. Effect of explant types and plant growth regulators on direct regeneration in medicinal plant Pogostemon cablin. Plant Omics J 7 (5): 322-327.

Maes L, Goossens A. 2010. Hormone-mediated promotion of trichome initiation in plants is conserved but utilized species and trichomespecific regulatory mechanisms. Plant Signal Behav 5 (2): 205-207.

Nichols L. 2018. The retention factor. Available online: chem.libretexts.org/Bookshelves/Organic_Chemistry/ [11 January 2018]

Nuryani Y, Emmyzar, Wiratno. 2005. Budidaya Tanaman Nilam. Balai Penelitian Tanaman Obat dan Aromatik, Balitbang Pertanian, Bogor.

Sahertian SM. 2015. Multiplikasi tunas in vitro Nilam Aceh (Pogostemon cablin Benth. var. Sidikalang) dan analisa kualitatif minyak nilam [Hon. Thesis]. Fakultas Teknobiologi, Universitas Surabaya, Surabaya [Indonesian].

Swamy MK, Sinniah UR. 2016. Patchouli (Pogostemon cablin Benth.): botany, agrotechnology, and biotechnological aspects. Industr Crops Prod 87: 161-176.

Triesty I, Mahfud. 2017. Ekstraksi minyak atsiri dari gaharu (Aquilaria malaccensis) dengan menggunakan metode microwave hydrodistillation dan soxhlet extraction. Jurnal Teknik ITS 6 (2): F392-F395. [Indonesian]

Vyas S, Rao MS, Suthar RK, Purohit SD. 2008. Liquid culture system stimulates in vitro growth and shoot multiplication in four medicinally important plants. Med Aromatic Plant Sci Biotechnol 2 (2): 96-100.

Wu YG, Li CG, Li XC, Yuan M, Hu XW. 2013. Comparison of essential oil composition between Pogostemon cablin and Agastache rugosa used as herb. J Essent Bearing Plants 16: 705-713.

Yang X, Zhang X, Yang SP, Liu WQ. 2013. Evaluation of the antibacterial activity of patchouli oil. Iranian $\mathrm{J}$ Pharmaceut Res 12 (3): 307-316. 